Exploring classroom discourse: Language in action by

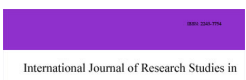
Language Learning Steve Walsh (2011)

Kia Heirati, Javad

University of Mazandaran, Babolsar,Iran (Javad.kiaheirati@yahoo.com)

Kia Heirati, Hamideh

Shahed School, Iran (Hamideh.kiaheirati@yahoo.com)
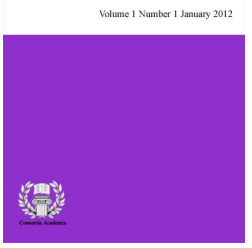

ISSN: 2243-7754 Online ISSN: 2243-7762

Received: 2 September 2015

Revised: 20 September 2015

Accepted: 2 November 2015

OPEN ACCESS

\title{
Abstract
}

The central aim of this book is to give teachers an insight to make them aware of what is going on in their classrooms. As Walsh mentions that the central thesis of the book is that "language teachers can improve their professional practice by developing a closer understanding of classroom discourse and, in particular, by focusing on the complex relationship between language, interaction and learning" (p. 1). Providing a framework (self-evaluation of teacher talk or SETT model) for language teachers, he aims at raising the awareness of language teachers about their actions in the classroom. Another term in line with SETT framework is the notion of CIC (classroom interactional competence) that guides the teachers to use interaction as a tool to give their learners enough opportunities for learning.

Keywords: classroom discourse; teacher talk; SETT framework; CIC 


\section{Exploring classroom discourse: Language in action by Steve Walsh (2011)}

\section{Review of the chapters}

The book consists of an introductory chapter, seven topic-based chapters, and a set of conclusions. The introduction maneuvers on various terms and propositions which the author develops at greater length later. For instance, he first mentions CIC on page one or something about the SETT framework "as a means of helping practitioners evaluate their own use of language while teaching" (p. 1). In fact, Walsh, in the introduction part, is paving the way for starting his argument in favor of awareness-raising to be formed in the teachers. He presents some significant features of interaction: control of patterns or communication, teachers' modified language, elicitation and repair. He also mentions another structure of classroom discourse called as IRF (initiation, response, feedback) exchange, which was first proposed by Siclair and Coulthard (1975) that is one of the most common discourse structure found in classrooms all over the world. As a whole, the book attempts to show how teachers can begin to achieve more sophisticated understanding of classroom discourse in order to be able to manage the interaction.

Chapter Two looks into the relationship between classroom discourse and teaching. In this chapter, Walsh stresses that "successful language teaching entails using linguistic resources that are 'fit for purpose', that enable pedagogic goals and language use to coincide. This is a point which in Chapter Six he introduces the term "mode convergent" (p. 35). Walsh put this argument at the center of this chapter that interaction lies at the heart of effective classroom practice. It seems he aims at making the teachers awake by studying the specific interactional strategies they use, "they can promote active, engaged and dialogic learning environments" (p. 47).

Chapter Three examines the relationship between interaction and language learning. The focus of this chapter is to introduce interaction as central part in learning to be occurred. As Van Lier (1996, p. 5) mentions that "interaction is the most important element in the curriculum". Walsh ends the chapter by stating that "interaction in the second language classroom is fundamental to language acquisition" (p. 66) and providing learning opportunities lies at the responsibility of the teacher This chapter also emphasizes the role of teacher in providing "scaffolding"-briefly defined here as "linguistic support given by a tutor to a learner" (p. 64) and a socio-cultural view of learning which emphasizes the fact that learning is seen as a social process rather than a cognitive one.

Chapter Four is concerned with approaches to investigate classroom discourse. Walsh begins with consideration of various ways of recording what goes on in the classroom (audio, video, written narrative, and so on) and examines the pros and cons of each. He further emphasizes the methodology that should be chosen in order to analyze the classroom discourse. In fact, depending on the question of the researcher, the desired methodology is selected, and this methodology can take different forms. We should put this point in mind that each question doesn't go with one specific method. In fact, selection of methodology depends on the expectations and the limitation of the atmosphere of the classroom, hence, the methodology selected shouldn't give us an inappropriate definition. If our method has weaknesses, it has lots of effects. Walsh argues that conversation analysis (CA), unlike discourse analysis, does not impose pre-constructed framework on classroom data and instead "attempts to account for the practices at work that enable participants in a conversation to make sense of the interaction and contribute to it" (p. 86).

Chapter Five presents an alternative approaches in order to take classroom discourse into account and contains substantial section on corpus linguistics. The chapter suggests that combining a corpus linguistics approach with a conversation analysis approach (CLCA) can be a productive way of analyzing classroom discourse, as the latter can uncover the main secrets of classroom discourse and what goes on during the class conversation between teachers and the students in the classroom. 
In Chapter Six, Walsh proposes the central thesis of the book: the SETT model. Studying this model a teacher can obtain some interesting facts about the classroom he is dealt with. This model emphasizes the fact that there must be an alignment between teachers' pedagogic goal and the interactional features applied by them in the class in order to make their actions mode convergent. It labels teacher classroom activity via four modes (managerial mode; materials mode; skills and systems mode; and classroom context mode). Walsh also notes that his model is tended to be representative rather than comprehensive.

Chapter Seven makes this point that teachers are often encouraged to reflect on their practice. Walsh implies that the teacher must be aware of his work in the classroom and this awareness should create a positive effect for learners. Conducting reflective practice (RP) requires teachers to conduct action research. Reflective teachers can exploit three conditions to create such awareness: a tool that guides their accomplishment in the classroom, a meta-language that involve the specific language, which is higher than the instructional level used within the instruction, and a dialogue with a supportive colleague that causes us to reach to a deep structure of our classes.

Chapter eight deals with the key concept titled as CIC. Walsh defines classroom interactional competence as “teachers and learners' ability to use interaction as a tool for mediating and assisting learning" (p. 158). Walsh offers a helpful distinction of interactional competence and communicative competence. He also proposes the main features of classroom interactional competence as being mode convergent, wait time, and shaping learner's contribution by scaffolding. In fact, there should be a concern for teachers to decide for themselves how to improve their CIC. CIC, as Walsh argues, creates better learning opportunity for learners.

The last chapter of the book, which deals with the conclusions, presents this fact that the most prevalent structure of classrooms around the world is the IRF exchange structure. Walsh states that "the aim should be to collect small amounts of data from a sample of lessons and build up a profile of a teacher's classroom interactional competence" (p. 190). In his view, teachers should facilitate the 'jagged' classroom interaction, and learners must be encouraged to resist their socialization as attentive non-initiators.

\section{Conclusion}

In fact, this book aims at making the teachers to be familiar with the facts of classroom and that how teachers can face improvement upon their teaching by adhering to the SETT model and this point that how reflective teachers can have a better contemplation of teaching under the notion of CIC whether it makes an intervention in their process or failure. Becoming a teacher Walsh implies that requires lot of responsibilities on the teacher's shoulder that he should be aware of how to deal with them.

\section{References}

Sinclair, J., \& Coulthhard, M. (1975). Towards an analysis of discourse. Oxford University Press: Oxford.

Van Lier, L. (1996). Interaction in the language curriculum: Awareness, autonomy and authenticity. New York: Longman.

Walsh, S. (2011). Exploring classroom discourse: Language in action. London and New York: Routledge. 
Kia Heirati, J., \& Kia Heirati, H. 